\title{
Flame Atomic Absorption Spectrometric Determination of Trace Amounts of Silver after Solid-Phase Extraction with 2-Mercaptobenzothiazole Immobilized on Microcrystalline Naphthalene
}

\author{
Farid Shakerian, Ali Mohammad Haji Shabani, \\ Shayessteh Dadfarnia, and Mahdieh Shabani \\ Department of Chemistry, Faculty of Science, Yazd University, Yazd 89195-741, Iran \\ Correspondence should be addressed to Shayessteh Dadfarnia; sdadfarnia@yazduni.ac.ir
}

Received 16 March 2013; Accepted 7 May 2013

Academic Editor: Esteban P. Urriolabeitia

Copyright (C) 2013 Farid Shakerian et al. This is an open access article distributed under the Creative Commons Attribution License, which permits unrestricted use, distribution, and reproduction in any medium, provided the original work is properly cited.

A simple and sensitive solid-phase extraction (SPE) procedure combined with flame atomic absorption spectrometry (FAAS) was designed for the extraction and determination of trace amounts of silver. A column of immobilized 2-mercaptobenzothiazole (MBT) on microcrystalline naphthalene was used as the sorbent. Silver was quantitatively retained on the column in the $\mathrm{pH}$ range of 0.5-6.0. After extraction, the solid mass consisting of silver complex and naphthalene was dissolved out of the column with $5.0 \mathrm{~mL}$ of dimethylformamide, and the analyte was determined by flame atomic absorption spectrometry (FAAS). Under the optimum experimental conditions, the adsorption capacity was found to be $1.18 \mathrm{mg}$ of silver per gram of the sorbent. A sample volume of $800 \mathrm{~mL}$ resulted in a preconcentration factor of 160 . The relative standard deviation obtained for ten replicate determinations at a concentration of $0.8 \mu \mathrm{g} \mathrm{L}^{-1}$ was $1.4 \%$, and the limit of detection was $0.02 \mu \mathrm{g} \mathrm{L}^{-1}$. The method was successfully applied to the determination of silver in radiology film, waste water, and natural water samples. The accuracy was examined by recovery experiments, independent analysis by electrothermal atomic absorption spectrometry, and analysis of two certified reference materials.

\section{Introduction}

Silver and its compounds have an essential role in electronic and electrical applications, photographic film production, dental and pharmaceutical preparations, and manufacturing of fungicides [1,2]. Silver is also used for the preparation of high-strength and corrosion-resistance alloys and jewelry. These widespread applications have resulted in an increased silver content of the environmental samples. Silver can also enter the environment via industrial waters because it is often an impurity in zinc, copper, antimony, and arsenic ores [3]. On the other hand, silver has been recognized as a toxic element to many aquatic organisms even at low concentrations [4]. Moreover, Ag accumulation in the human body may lead to a permanent blue-gray skin discoloration (known as Argyria), and the threshold values regulating the maximum amount of silver permitted in different kinds of samples have been established in many countries [5]. Therefore, its trace determination in water and environmental samples is important.

Flame atomic absorption spectrometry is often accepted as a suitable instrumental technique for the measurement of silver because of its speed and ease of operation. However, it has the major drawback of low sensitivity for direct determination of silver in complex matrices [6]. Therefore, a separation/preconcentration step is often required prior to the ultra-trace determination of silver. The most widely used methods for the separation and preconcentration of the trace 
amounts of silver ions are solid-phase extraction (SPE) $[7,8]$, solvent extraction [9], cloud-point extraction (CPE) [4], and dispersive liquid-liquid microextraction [10]. Among these methods, solid-phase extraction has gained rapid acceptance due to its simplicity, flexibility, high enrichment factor, and short analysis time. Appropriate organic ligands can be chemically or physically supported on various substrates, thus providing complexing or chelating sorbents for the separation and preconcentration of metal ions. Naphthalene is known as an excellent extractant at high temperature, but the procedure is time consuming and cannot be applied to thermally unstable complexes [11]. The extraction of metal chelates with microcrystalline naphthalene by adding an acetone solution of naphthalene is more rapid [12]. In recent years, column extraction of metal ions with modified microcrystalline naphthalene has attracted many researchers $[13,14]$.

2-Mercaptobenzothiazole (MBT) with sulfur and nitrogen donor atoms is known to form stable complexes with various metal ions. MBT is insoluble in water but soluble in many organic solvents. Thus, it can be applied to the separation and preconcentration of trace amounts of metals present in aqueous solutions. MBT has been used as the chelating agent for the preconcentration and spectrometric determination of $\mathrm{Ag}(\mathrm{I})$ [15-17], $\mathrm{Cu}(\mathrm{II})$ [18], $\mathrm{Hg}(\mathrm{II})[19,20]$, $\mathrm{Au}(\mathrm{III}), \mathrm{Pt}(\mathrm{IV})$, and $\mathrm{Pd}(\mathrm{II})$ [21]. It has also been used in the construction of ion-selective and modified electrodes $[22,23]$.

In this study, a simple and efficient method for the selective separation and preconcentration of silver from a large volume of aqueous solution using a column of immobilized 2-mercaptobenzothiazole on microcrystalline naphthalene is described. The solid mass consisting of the silver complex and microcrystalline naphthalene is easily dissolved out of the column with a small volume of dimethylformamide (DMF), and the analyte is determined by flame atomic absorption spectrometry.

\section{Experimental}

2.1. Reagents. All of the chemicals were of the highest purity available from the Merck Company (Darmstadt, Germany) and were used without any further purification. Double distilled water was used throughout the experiments. A stock solution of $1000 \mathrm{mg} \mathrm{L}^{-1}$ of silver ion was prepared by dissolving an appropriate amount of $\mathrm{AgNO}_{3}$ in water. Working solutions were prepared daily from the stock solution by appropriate dilution with distilled water.

2.2. Apparatus. An Analytikjena novAA 300 (model 330, Germany) atomic absorption spectrometer furnished with a silver hollow-cathode lamp and air-acetylene flame was used for all of the absorption measurements. The hollowcathode lamp current was $4.0 \mathrm{~mA}$, the wavelength was set at $328.1 \mathrm{~nm}$, and the slit width was $1.2 \mathrm{~nm}$. The $\mathrm{pH}$ measurements were carried out by a Metrohm $\mathrm{pH}$ meter (model 691, Switzerland) using a combined glass-calomel electrode.
2.3. Preparation of the Sorbent. MBT $(0.4 \mathrm{~g})$ and naphthalene (20 g) were dissolved in a hundred milliliters of acetone and then mixed with a magnetic stirrer at $35^{\circ} \mathrm{C}$ for 5 minutes. The mixture was then slowly added to $1000 \mathrm{~mL}$ of double distilled water at room temperature. The mixture was stirred for about 1 hour and was left aside for 120 minutes. Then, it was filtered through a sintered-glass funnel using the vacuum pump, and the residue was washed with distilled water for several times. Finally, the prepared sorbent was air dried and kept in a closed brown bottle for the subsequent use. The color of the prepared sorbent was yellow and it was stable at least for two months.

2.4. Procedure. The $\mathrm{pH}$ of an aliquot of the sample or standard solution containing $0.2-20.0 \mu \mathrm{g}$ of silver was adjusted at $\sim 1$ with an appropriate amount of nitric acid. The solution was passed through a glass column packed with the MBT immobilized on the microcrystalline naphthalene $(20 \mathrm{~mm} \times 10 \mathrm{~mm}$ i.d.) at a flow rate of $10.0 \mathrm{~mL} \mathrm{~min}^{-1}$ with the aid of a suction pump. The column was washed with a small amount of water, and the sorbent was pushed down with a flat glass rod to remove the excess of water attached to naphthalene. Finally, the solid mass consisting of the metal complex and naphthalene was dissolved with $5.0 \mathrm{~mL}$ of DMF, and the silver concentration in the resulting solution was determined by flame atomic absorption spectrometer.

2.5. Preparation of Water Samples. Water samples were filtered through $0.45 \mu \mathrm{m}$ membrane Millipore filter. The $\mathrm{pH}$ was adjusted to $\sim 1.0$ with nitric-acid solution, and the analyte was determined according to the given procedure.

2.6. Preparation of Radiology Film. The proper amount of radiology film was washed with distilled water and dry ashed in a muffle furnace at $550^{\circ} \mathrm{C}$ for $60 \mathrm{~min}$. The residue was treated with $10 \mathrm{~mL}$ of nitric-acid solution $\left(6 \mathrm{~mol} \mathrm{~L}^{-1}\right)$ and evaporated to dryness at a low heating rate. The residue was dissolved in $80 \mathrm{~mL}$ of distilled water, filtered, and adjusted to $\mathrm{pH} 1.0$ using nitric-acid solution. The clear solution was transferred into a $100 \mathrm{~mL}$ volumetric flask and diluted to mark with distilled water.

2.7. Certified Reference Materials. To proper amount of CPB-1 (Composition: $\mathrm{Pb}=64.74 \pm 0.12 \%, \mathrm{~S}=17.8 \pm 0.2 \%, \mathrm{Fe}=8.48 \pm$ $0.06 \%, \mathrm{Zn}=4.42 \pm 0.04 \%, \mathrm{SiO}_{2}=0.74 \pm 0.04 \%, \mathrm{Sb}=0.36 \pm$ $0.03 \%, \quad \mathrm{Al}_{2} \mathrm{O}_{3}=0.28 \pm 0.02 \%, \quad \mathrm{Cu}=0.254 \pm 0.004 \%$, As $=0.056 \pm 0.004 \%, \mathrm{Mn}=0.039 \pm 0.002 \%, \mathrm{Bi}=0.023 \pm$ $0.002 \%, \mathrm{Sn}=0.019 \pm 0.005 \%, \mathrm{Cd}=0.0143 \pm 0.002 \%, \mathrm{Ag}=$ $626 \pm 6 \mu \mathrm{gg}^{-1}, \mathrm{Se}=30 \pm 3 \mu \mathrm{gg}^{-1}$, and $\left.\mathrm{Hg}=5.5 \pm 0.5 \mu \mathrm{gg}^{-1}\right)$ or BCR No. 288 (Composition: $\mathrm{Ag}=30.5 \pm 0.5 \mu \mathrm{gg}^{-1}$, As $=55.7 \pm 1.6 \mu \mathrm{gg}^{-1}, \mathrm{Bi}=215.8 \pm 2.4 \mu \mathrm{gg}^{-1}, \mathrm{Cd}=33.3 \pm$ $0.9 \mu \mathrm{gg}^{-1}, \mathrm{Cu}=19.3 \pm 0.4 \mu \mathrm{gg}^{-1}, \mathrm{Ni}=4.57 \pm 0.11 \mu \mathrm{gg}^{-1}$, $\mathrm{Sb}=32.5 \pm 0.9 \mu \mathrm{gg}^{-1}, \mathrm{Se}<0.2 \mu \mathrm{gg}^{-1}, \mathrm{Sn}=30.6 \pm 1.5 \mu \mathrm{g} \mathrm{g}^{-1}$, $\mathrm{Te}=32.8 \pm 1.3 \mu \mathrm{gg}^{-1}, \mathrm{Tl}=2.3 \pm 0.1 \mu \mathrm{gg}^{-1}$, and $\mathrm{Zn}=8.2 \pm$ $0.4 \mu \mathrm{g} \mathrm{g}^{-1}$ ), $5 \mathrm{~mL}$ of concentrated nitric acid was added and the solution was heated. Then, $3 \mathrm{~mL}$ of hydrogen peroxide was added, and the mixture was heated near to dryness. 
The solution was diluted with distilled water and was filtered. The $\mathrm{pH}$ was adjusted to $\sim 1$, and the solution was diluted to $100 \mathrm{~mL}$ in a conical flask.

\section{Results and Discussion}

The aim of this study was to develop a sensitive method for the separation and preconcentration of trace amounts of silver ions from an aqueous solution based on the selective adsorption of silver on a column packed with MBT immobilized on the microcrystalline naphthalene. MBT forms a strong waterinsoluble complex with silver ions and permits the separation of silver at low $\mathrm{pH}$. In order to obtain the best conditions for the extraction of silver, the procedure was optimized by the univariable method.

3.1. Influence of $p H$. The effect of the sample $\mathrm{pH}$ on the retention of silver was studied by varying the $\mathrm{pH}$ within the range of $0.5-9.0$. The results showed (Figure 1) that the recovery of silver was maximized in the $\mathrm{pH}$ range of $0.5-$ 6.0. The decrease in the extraction efficiency at $\mathrm{pH}>6.0$ is probably due to the precipitation of silver as its hydroxide. Thus, in order to achieve the maximum efficiency and selectivity of the silver extraction, a $\mathrm{pH}$ of $\sim 1.0$ was selected for the subsequent studies.

3.2. Choice of Solvent. The choice of an appropriate solvent for dissolving the $\operatorname{Ag}(\mathrm{I})-\mathrm{MBT}$ along with naphthalene is an important factor. The solvent should completely dissolve the content of the column and should not interfere with the detection system; thus, with FAAS determination it must efficiently burn during the analysis of the sample. Various solvents were tested for dissolving the complex of Ag(I)-MBT immobilized on naphthalene. The solid material was insoluble in toluene, $n$-hexane, methyl isobutyl ketone, dioxane, and chloroform; however, it was readily dissolved in acetone, acetonitrile, and dimethylformamide (DMF). DMF was chosen because of its high capability in dissolving the sorbent, high stability, and compatibility with the FAAS. Furthermore, $5.0 \mathrm{~mL}$ of this solvent was found to be sufficient for complete dissolution of the solid mass.

3.3. Effect of Sample Flow Rate. Another important factor influencing the extraction efficiency and the speed of the analysis is the sample flow rate. In order to have a good precision, as well as sensitivity and speed, it is necessary to select a flow rate that guarantees the achievement of the equilibrium between the sample and the sorbent. The effect of the flow rate on the extraction recovery of silver was examined by varying the flow rate from 0.5 to $25.0 \mathrm{~mL} \mathrm{~min}^{-1}$ under constant experimental conditions. The outcome showed that (Figure 2) the extraction was relatively fast, and up to the sample flow rate of $12.0 \mathrm{~mL} \mathrm{~min}^{-1}$ the uptake of silver was constant and independent of the flow rate. Therefore, a sample flow rate of $10.0 \mathrm{~mL} \mathrm{~min}^{-1}$ was selected in further studies.

3.4. Effect of Sample Volume. In order to explore the possibility of enriching the trace amount of silver from the

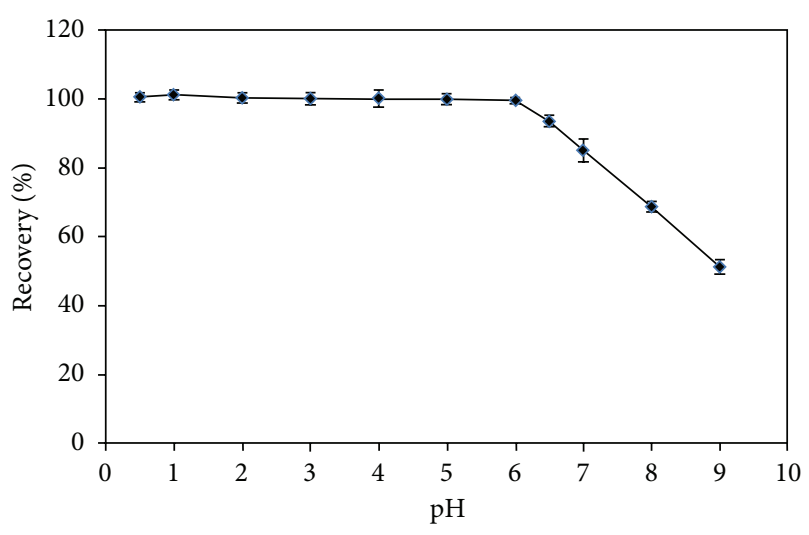

FIGURE 1: Effect of $\mathrm{pH}$ on the recovery of silver. Conditions: amount of silver $10 \mu \mathrm{g}$; sample volume $50 \mathrm{~mL}$; sample flow rate $5.0 \mathrm{~mL} \mathrm{~min}{ }^{-1}$; solvent for dissolving adsorbent DMF $(5.0 \mathrm{~mL})$.

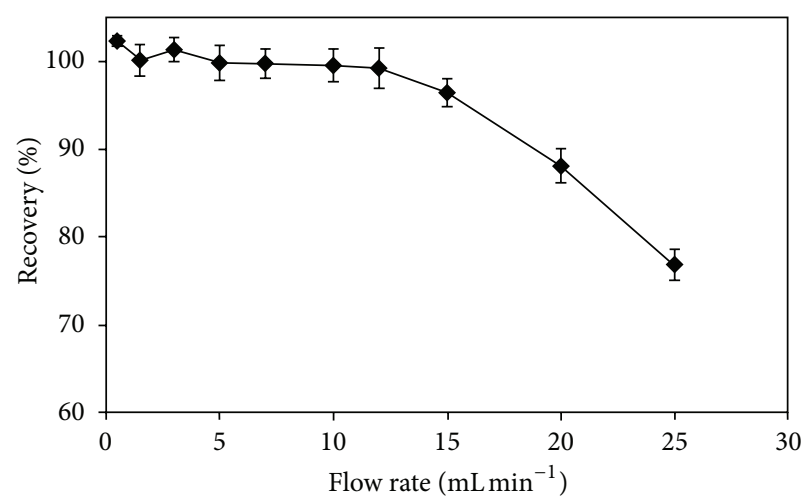

FIGURE 2: Effect of sample flow rate on the recovery of silver. Conditions: amount of silver $10 \mu \mathrm{g}$; sample volume $50 \mathrm{~mL}$; $\mathrm{pH} \sim 1.0$; solvent for dissolving adsorbent DMF $(5 \mathrm{~mL})$.

large sample volume, different sample volume (50-1000 mL) containing $10 \mu \mathrm{g}$ of silver was passed through the column. The retained analyte was then eluted with $5.0 \mathrm{~mL}$ of DMF, and the concentration of silver was determined. The results (Figure 3 ) showed that, up to an aqueous phase of $800 \mathrm{~mL}$, the recovery was quantitative $(\geq 95 \%)$. Thus, the method has the capability of achieving a high preconcentration factor for silver ions.

3.5. Interferences Study. A possible concern was that whether the method can be employed for the determination of silver in real samples where other cations or anions might compete with the analyte and lower the extraction efficiency. For this reason, the effect of various ions on the recovery of $5 \mu \mathrm{g}$ of silver from $100 \mathrm{~mL}$ of aqueous sample solution at an initial mole ratio of 1000 (ion/silver) was studied. When the interference was observed, the concentration of the interfering ion was lowered. A relative error of less than $5 \%$ was considered to be within the range of experimental error. The results of these studies (Table 1) indicated that the presence of high concentrations of the possible interfering ions in the sample had no significant effect on 


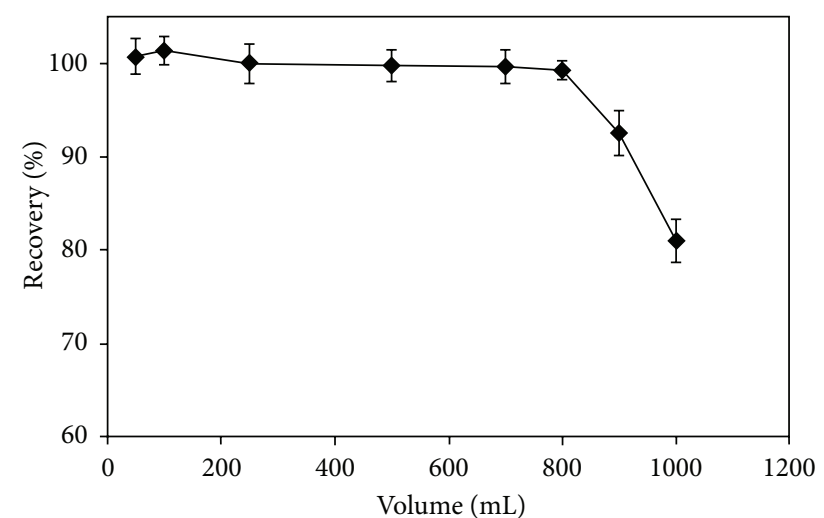

FIGURE 3: The influence of sample volume on the recovery of silver. Conditions: amount of silver $10 \mu \mathrm{g}$; sample flow rate $10.0 \mathrm{~mL} \mathrm{~min}{ }^{-1}$; $\mathrm{pH} \sim 1.0$; solvent for dissolving adsorbent DMF $(5.0 \mathrm{~mL})$.

TABLE 1: Effect of foreign ions on the recovery of $5 \mu \mathrm{g}$ of silver ions from $100 \mathrm{~mL}$ of aqueous solution.

\begin{tabular}{lcc}
\hline Foreign ion & Mole ratio $\left(\mathrm{M}^{n+} / \mathrm{Ag}^{+}\right)$ & Recovery $(\%)$ \\
\hline $\mathrm{K}^{+}$ & 1000 & $102.1 \pm 3.1$ \\
$\mathrm{Na}^{+}$ & 1000 & $99.9 \pm 1.5$ \\
$\mathrm{Mg}^{2+}$ & 1000 & $100.3 \pm 1.4$ \\
$\mathrm{Ca}^{2+}$ & 1000 & $99.7 \pm 3.5$ \\
$\mathrm{Ba}^{2+}$ & 1000 & $99.2 \pm 1.9$ \\
$\mathrm{Zn}^{2+}$ & 1000 & $99.4 \pm 2.6$ \\
$\mathrm{Co}^{2+}$ & 1000 & $102.8 \pm 1.4$ \\
$\mathrm{Ni}^{2+}$ & 1000 & $99.5 \pm 1.0$ \\
$\mathrm{~Pb}^{2+}$ & 1000 & $98.1 \pm 3.3$ \\
$\mathrm{Cu}^{2+}$ & 1000 & $97.7 \pm 2.1$ \\
$\mathrm{NO}_{3}{ }^{-}$ & 1000 & $97.6 \pm 2.8$ \\
$\mathrm{CH}_{3} \mathrm{COO}$ & $99.6 \pm 3.0$ \\
$\mathrm{SO}_{4}^{2-}$ & 1000 & $99.1 \pm 2.1$ \\
$\mathrm{Cr}^{3+}$ & 500 & $99.0 \pm 2.0$ \\
$\mathrm{Cd}^{2+}$ & 500 & $99.3 \pm 2.9$ \\
$\mathrm{Fe}^{3+}$ & 500 & $104.3 \pm 1.8$ \\
$\mathrm{Cl}^{-}$ & 500 & $99.2 \pm 1.0$ \\
$\mathrm{Hg}^{2+}$ & 50 & $97.3 \pm 1.0$ \\
\hline
\end{tabular}

the recovery of silver at trace levels. Furthermore, the effect of common ions present in the matrix of investigated samples such as $\mathrm{Na}^{+}, \mathrm{K}^{+}, \mathrm{Ca}^{2+}, \mathrm{Mg}^{2+}$, and $\mathrm{Pb}^{2+}$ at higher mole ratio (10000) was also considered, and no interference was observed. Thus, the method offers a high selectivity for silver ions.

3.6. Sorbent Capacity. The capacity of the sorbent for the retention of silver was determined. For this purpose, under the optimum $\mathrm{pH}, 1.0 \mathrm{~g}$ of the sorbent was added to the $100 \mathrm{~mL}$ of the solution containing $1500 \mu \mathrm{g}$ of silver, and it was mixed for 30 minutes. The sorbent was then separated and the concentration of silver remaining in solution was determined by FAAS. The capacity of the sorbent for silver was determined from the differences in the amount of the analyte in the initial and final solutions. The capacity of the sorbent for silver was found to be $1.18 \mathrm{mg} \mathrm{g}^{-1}$ of the sorbent.

3.7. Analytical Performance. Different concentrations of silver solution $(800 \mathrm{~mL})$ were processed according to the procedure, and it was found that the calibration graph exhibited linearity over the range of $0.15-25 \mu \mathrm{g} \mathrm{L}^{-1}$ of silver with a correlation coefficient of 0.9995 . The equation of the calibration curve was $A=0.0205 C+0.0009$ (where $A$ is the absorbance and $C$ is the concentration of silver in $\left.\mu \mathrm{g} \mathrm{L}^{-1}\right)$. The preconcentration factor defined as the ratio of the sample volume to the eluent volume was 160 . The relative standard deviation (RSD) for ten replicate measurements of $0.8 \mu \mathrm{g} \mathrm{L}^{-1}$ of silver was $1.4 \%$. The limit of detection defined as $3 s_{b} / m$ (where $s_{b}$ is the standard deviation of the blank and $m$ is the slope of the calibration curve) was $0.02 \mu \mathrm{g} \mathrm{L}^{-1}$.

3.8. Application. The procedure was applied to the determination of silver ions in rain water, the Damavand spring water, well water, river water (taken from Karaj rood, Karaj, Iran), waste water, and the radiology film sample. The reliability was checked by the recovery experiments, and the comparison of the results with the data was obtained by means of electrothermal atomic absorption spectrometry. The results of this investigation are indicated in Table 2. It can be seen that the recovery of the spiked sample is good, and at $95 \%$ confidence level there is no significant difference between the results of this study and the data obtained by electrothermal atomic absorption spectrometry. Furthermore, the proposed procedure was applied to the determination of silver in two certified reference materials, CPB-1 and BCR No. 288 with the silver concentration of $626.0 \pm 6.0 \mu \mathrm{gg}^{-1}$ and $30.5 \pm 0.5 \mu \mathrm{gg}^{-1}$, respectively. The concentrations of silver in CPB-1 and BCR No. 288 were found to be $618.0 \pm$ 2.5 and $30.2 \pm 0.8 \mu \mathrm{gg}^{-1}$, respectively, which are in good agreement with the accepted values. Thus, the method is suitable for the determination of silver in a wide range of samples.

3.9. Comparison of the Method with Other SPE Methods. The figures of merit of the proposed method and some other SPE methods combined with flame atomic absorption spectrometric for the determination of silver are summarized in Table 3. The proposed method in comparison with other methods showed some advantages such as a higher preconcentration factor and a lower detection limit.

\section{Conclusion}

The immobilized MBT on microcrystalline naphthalene is an effective sorbent for the separation and preconcentration of the trace amounts of silver ions from the aqueous solutions. The sorbent can selectively adsorb $\mathrm{Ag}(\mathrm{I})$ from the solution at low $\mathrm{pH}$. So, the other heavy metals do not significantly interfere. The main advantages of the proposed method are 
TABLE 2: Determination of silver in water samples and radiology film.

\begin{tabular}{|c|c|c|c|c|}
\hline Samples & Added $/ \mu \mathrm{g} \mathrm{L}^{-1}$ & Found $^{\mathrm{a}} / \mu \mathrm{g} \mathrm{L} \mathrm{L}^{-1}$ & Recovery (\%) & GFAAS $^{\mathrm{a}} / \mu \mathrm{g} \mathrm{L}^{-1}$ \\
\hline \multirow{2}{*}{ Well water } & 0 & $1.71 \pm 0.11$ & - & $1.68 \pm 0.06$ \\
\hline & 10 & $11.50 \pm 0.36$ & 97.9 & - \\
\hline \multirow{2}{*}{ Rain water } & 0 & $1.86 \pm 0.15$ & - & $1.91 \pm 0.08$ \\
\hline & 10 & $11.78 \pm 0.23$ & 99.2 & - \\
\hline \multirow{2}{*}{ River water } & 0 & $4.21 \pm 0.12$ & - & $4.16 \pm 0.19$ \\
\hline & 10 & $14.15 \pm 0.18$ & 99.4 & - \\
\hline \multirow{2}{*}{ Spring water } & 0 & $4.28 \pm 0.10$ & - & $4.47 \pm 0.16$ \\
\hline & 10 & $14.23 \pm 0.27$ & 99.5 & - \\
\hline \multirow{2}{*}{ Waste water } & 0 & $10.25 \pm 0.35$ & - & $10.16 \pm 0.45$ \\
\hline & 10 & $20.06 \pm 0.54$ & 98.1 & - \\
\hline \multirow{2}{*}{ Radiology film ${ }^{\mathrm{b}}$} & 0 & $2.11 \pm 0.16$ & - & $2.18 \pm 0.23$ \\
\hline & 1 & $3.07 \pm 0.35$ & 96.0 & - \\
\hline
\end{tabular}

${ }^{\mathrm{a}}$ Mean and standard deviation of three independent determinations; ${ }^{\mathrm{b}} \mathrm{mg} \mathrm{g}^{-1}$.

TABLE 3: A comparison between the figures of merit of the proposed method with similar SPE methods for Ag determination by FAAS.

\begin{tabular}{|c|c|c|c|c|c|}
\hline Sorbent material & Reagent & $\mathrm{pH}$ & $\mathrm{PF}$ & $\mathrm{DL} / \mu \mathrm{g} \mathrm{L}^{-1}$ & Reference \\
\hline Polystyrene-divinylbenzene & 6-Mercaptopurine & $5.5-6.0$ & - & 29 & {$[24]$} \\
\hline Silica gel & 2,4,6-Trimorpholino-1,2,3-triazin & $3.0-6.0$ & 130 & - & {$[25]$} \\
\hline Silica gel & MBT & $\mathrm{AM}$ & - & 0.66 & {$[15]$} \\
\hline Alumina & MBT & $1.0-6.0$ & 100 & - & {$[16]$} \\
\hline Alumina & Dithizone & $1.0-9.0$ & 100 & - & [26] \\
\hline Alumina & DDTC & $1.0-7.0$ & 125 & 0.7 & {$[7]$} \\
\hline Multiwalled carbon nanotubes & - & $7.0-9.0$ & 50 & 0.6 & [27] \\
\hline Moringa oleifera seeds & - & $6.0-8.0$ & 35 & 0.22 & {$[28]$} \\
\hline Naphthalene & MBT & $0.5-6.0$ & 160 & 0.02 & This work \\
\hline
\end{tabular}

PF: preconcentration factor; DL: detection limit; Pb-DDTC: lead diethyl dithiocarbamate; MBT: 2-mercaptobenzothiazole; DDTC: diethyl dithiocarbamate; AM: acidic medium $\left(0.05-6 \mathrm{~mol} \mathrm{~L}^{-1}\right.$ nitric acid).

the following: the ease of preparation of the sorbent, the high preconcentration factor (160), and the low detection limit $\left(0.02 \mu \mathrm{g} \mathrm{L}^{-1}\right)$ which is suitable for the determination of silver in different real samples.

\section{References}

[1] M. Grayson, Kirk-Othmer Encyclopedia of Chemical Technology, vol. 21, John Wiley \& Sons, New York, NY, USA, 3rd edition, 1980.

[2] I. C. Smith and B. L. Carson, Trace Metals in the Environment, vol. 2, Ann Arbor Science Publishers, Ann Arbor, Mich, USA, 1977.

[3] R. Soager, Metallic Raw Materials Dictionary, Bank Tobel, Zurich, Switzerland, 1984.

[4] J. L. Manzoori, H. Abdolmohammad-Zadeh, and M. Amjadi, "Ultra-trace determination of silver in water samples by electrothermal atomic absorption spectrometry after preconcentration with a ligand-less cloud point extraction methodology," Journal of Hazardous Materials, vol. 144, no. 1-2, pp. 458-463, 2007.

[5] M. Resano, M. Aramendía, E. García-Ruiz, C. Crespo, and M. A. Belarra, "Solid sampling-graphite furnace atomic absorption spectrometry for the direct determination of silver at trace and ultratrace levels," Analytica Chimica Acta, vol. 571, no. 1, pp.142$149,2006$.

[6] C. K. Christou and A. N. Anthemidis, "Flow injection online displacement/solid phase extraction system coupled with flame atomic absorption spectrometry for selective trace silver determination in water samples," Talanta, vol. 78, no. 1, pp. 144149, 2009.

[7] S. Dadfarnia, A. M. Haji Shabani, and M. Gohari, "Trace enrichment and determination of silver by immobilized DDTC microcolumn and flow injection atomic absorption spectrometry," Talanta, vol. 64, no. 3, pp. 682-687, 2004.

[8] A. A. Hill, R. J. Lipert, and M. D. Porter, "Determination of colloidal and dissolved silver in water samples using colorimetric solid-phase extraction," Talanta, vol. 80, no. 5, pp. 1606-1610, 2010.

[9] T. Koh and T. Sugimoto, "Extractive spectrophotometric determination of silver(I) at the $10^{-7} \mathrm{M}$ level using 1,10phenanthroline and tetrabromophenolphthalein ethyl ester," Analytica Chimica Acta, vol. 333, no. 1-2, pp. 167-173, 1996.

[10] S. Jafarvand, A. Bidari, P. Hemmatkhah, M. R. M. Hosseini, and Y. Assadi, "Dispersive liquid-liquid microextraction of silver prior to determination by microsample introductionflame atomic absorption spectrometry," Analytical Letters, vol. 42, no. 14, pp. 2214-2231, 2009. 
[11] A. Wasey, R. K. Bansal, B. K. Puri, and A. L. J. Rao, "Spectrophotometric determination of osmium with 1-phenyl4,4,6-trimethyl-( $1 \mathrm{H}, 4 \mathrm{H})$-2-pyrimidinethiol and extraction into molten naphthalene," Talanta, vol. 31, no. 3, pp. 205-206, 1984.

[12] R. K. Dubey, A. Bhalotra, M. K. Gupta, and B. K. Puri, "Differential pulse polarographic determination of rhodium(III) and ruthenium(III) in synthetic samples after preconcentration of their quinolin-8-olate complexes onto microcrystalline naphthalene," Microchemical Journal, vol. 58, no. 1, pp. 117-126, 1998.

[13] A. M. H. Shabani, S. Dadfarnia, and N. Nasirizadeh, "Speciation analysis of mercury in water samples by cold vapor atomic absorption spectrometry after preconcentration with dithizone immobilized on microcrystalline naphthalene," Analytical and Bioanalytical Chemistry, vol. 378, no. 5, pp. 1388-1391, 2004.

[14] B. Rezaei, S. Meghdadi, and N. Majidi, "Preconcentration of thallium(III) with 2,6-bis(N-phenyl carbamoyl) pyridine on microcrystalline naphthalene prior to its trace determination in human serum spectrophotometrically," Spectrochimica Acta A, vol. 67, no. 1, pp. 92-97, 2007.

[15] Q. Pu and Q. Sun, "Application of 2-mercaptobenzothiazolemodified silica gel to on-line preconcentration and separation of silver for its atomic absorption spectrometric determination," Analyst, vol. 123, no. 2, pp. 239-243, 1998.

[16] G. Absalan and M. A. Mehrdjardi, "Separation and preconcentration of silver ion using 2-mercaptobenzothiazole immobilized on surfactant-coated alumina," Separation and Purification Technology, vol. 33, no. 1, pp. 95-101, 2003.

[17] A. Safavi, N. Iranpoor, and N. Saghir, "Directly silica bonded analytical reagents: synthesis of 2-mercaptobenzothiazole-silica gel and its application as a new sorbent for preconcentration and determination of silver ion using solid-phase extraction method," Separation and Purification Technology, vol. 40, no. 3, pp. 303-308, 2004.

[18] Y. S. Choi and H. S. Choi, "Sensitized spectrophotometric determination of trace $\mathrm{Cu}(\mathrm{II})$ in cationic surfactant media," Bulletin of the Korean Chemical Society, vol. 24, no. 2, pp. 222224, 2003.

[19] J. Chwastowska, A. Rogowska, E. Sterlińska, and J. Dudek, "Chelating 2-mercaptobenzothiazole loaded resin. Application to the separation of inorganic and alkylmercury species for their atomic absorption spectrometry determination in natural waters," Talanta, vol. 49, no. 4, pp. 837-842, 1999.

[20] D. Pérez-Quintanilla, I. del Hierro, M. Fajardo, and I. Sierra, "Preparation of 2-mercaptobenzothiazole-derivatized mesoporous silica and removal of $\mathrm{Hg}$ (II) from aqueous solution," Journal of Environmental Monitoring, vol. 8, no. 1, pp. 214-222, 2006.

[21] Q. Pu, Z. Su, Z. Hu, X. Chang, and M. Yang, "2-Mercaptobenzothiazole-bonded silica gel as selective adsorbent for preconcentration of gold, platinum and palladium prior to their simultaneous inductively coupled plasma optical emission spectrometric determination," Journal of Analytical Atomic Spectrometry, vol. 13, no. 4, pp. 249-253, 1998.

[22] S. M. Golabi and J. Mohammadi, "Wire-coated silver(I) ionselective electrode based on 2-mercaptobenzothiazole (MBT) ionophore: application to the determination of silver in real samples," Analytical Sciences, vol. 19, no. 6, pp. 877-881, 2003.

[23] R. K. Shervedani and M. K. Babadi, "Application of 2mercaptobenzothiazole self-assembled monolayer on polycrystalline gold electrode as a nanosensor for determination of Ag(I)," Talanta, vol. 69, no. 3, pp. 741-746, 2006.
[24] B. C. Mondal, D. Das, and A. K. Das, "Application of a new resin functionalised with 6-mercaptopurine for mercury and silver determination in environmental samples by atomic absorption spectrometry," Analytica Chimica Acta, vol. 450, no. 1-2, pp. 223-230, 2001.

[25] T. Madrakian, A. Afkhami, M. A. Zolfigol, and M. Solgi, "Separation, preconcentration and determination of silver ion from water samples using silica gel modified with 2,4,6trimorpholino-1,3,5-triazin," Journal of Hazardous Materials, vol. 128, no. 1, pp. 67-72, 2006.

[26] G. Absalan and A. Aghaei Goudi, "Optimizing the immobilized dithizone on surfactant-coated alumina as a new sorbent for determination of silver," Separation and Purification Technology, vol. 38, no. 3, pp. 209-214, 2004.

[27] Q. Ding, P. Liang, F. Song, and A. Xiang, "Separation and preconcentration of silver ion using multiwalled carbon nanotubes as solid phase extraction sorbent," Separation Science and Technology, vol. 41, no. 12, pp. 2723-2732, 2006.

[28] C. S. T. Araújo, V. N. Alves, H. C. Rezende, and N. M. M. Coelho, "Development of a flow system for the determination of low concentrations of silver using Moringa oleifera seeds as biosorbent and flame atomic absorption spectrometry," Microchemical Journal, vol. 96, no. 1, pp. 82-85, 2010. 

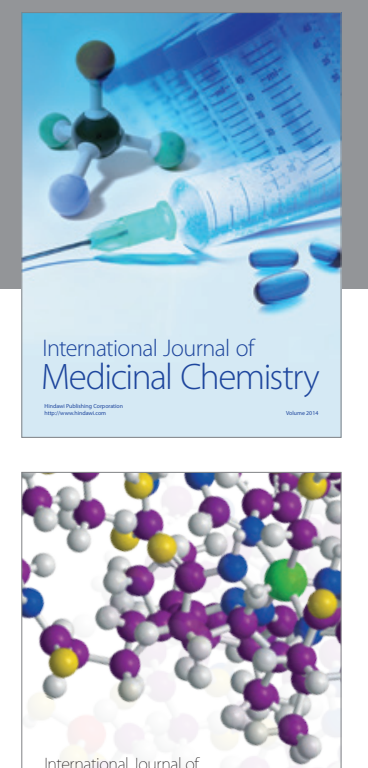

\section{Carbohydrate} Chemistry

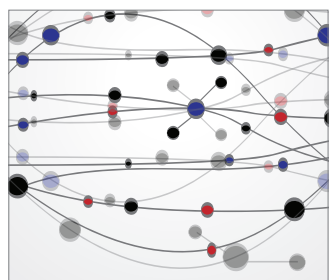

The Scientific World Journal
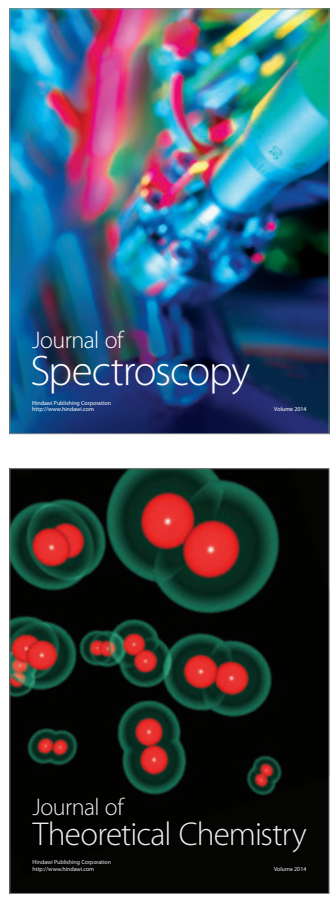
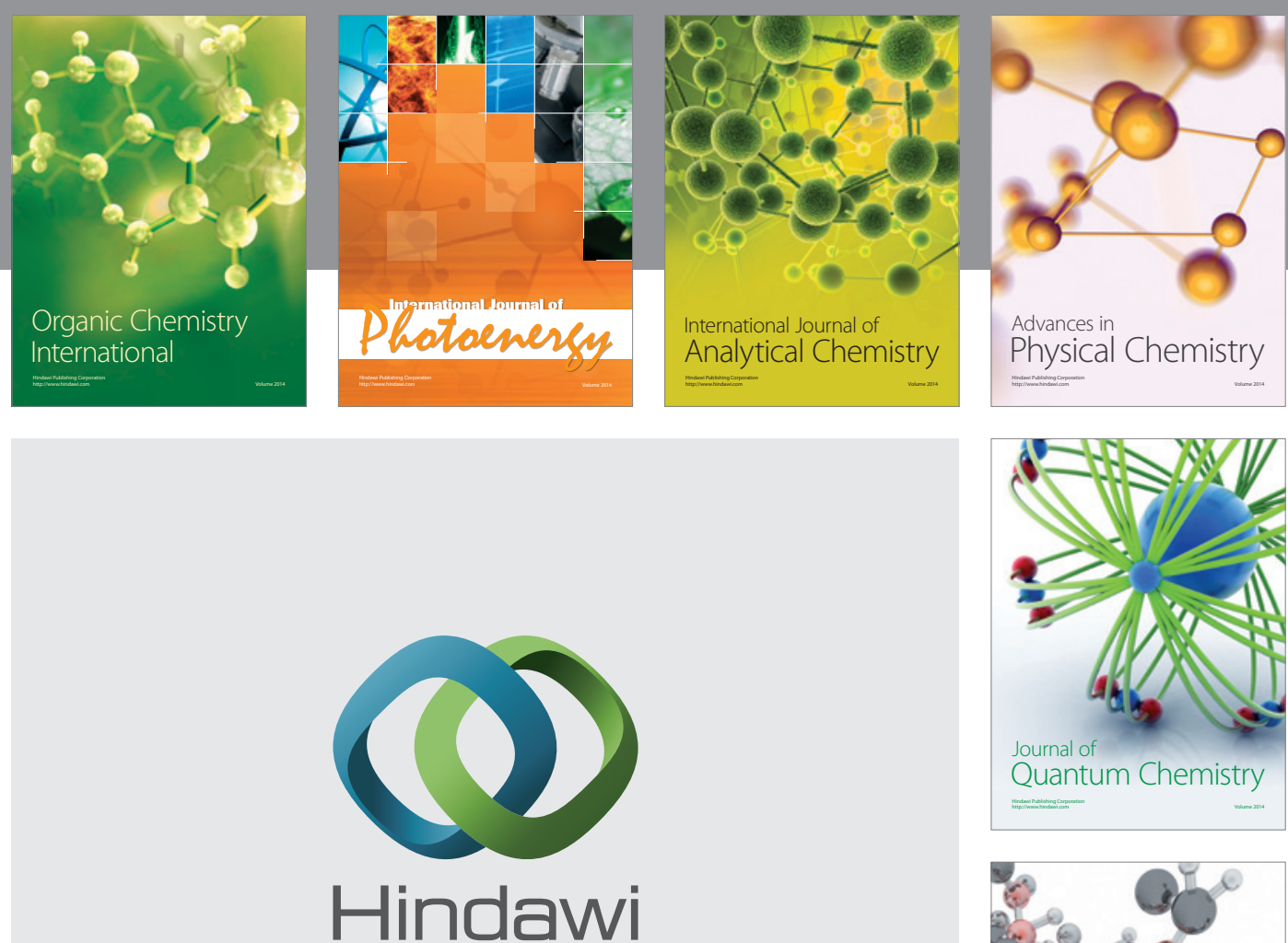

Submit your manuscripts at

http://www.hindawi.com

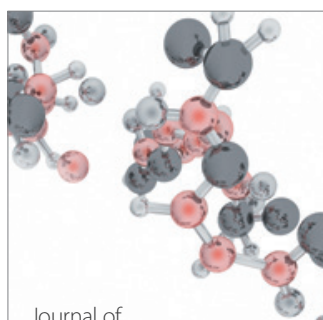

Analytical Methods

in Chemistry

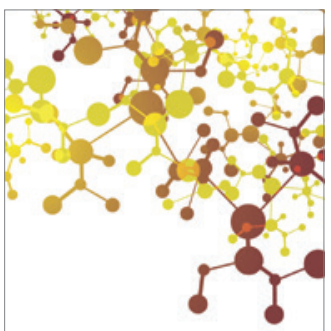

Journal of

Applied Chemistry

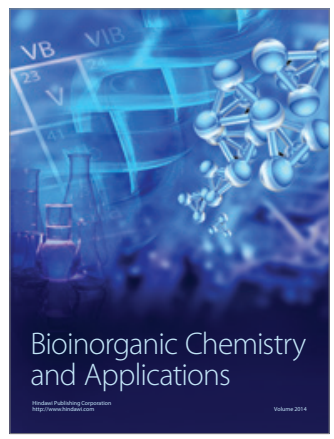

Inorganic Chemistry
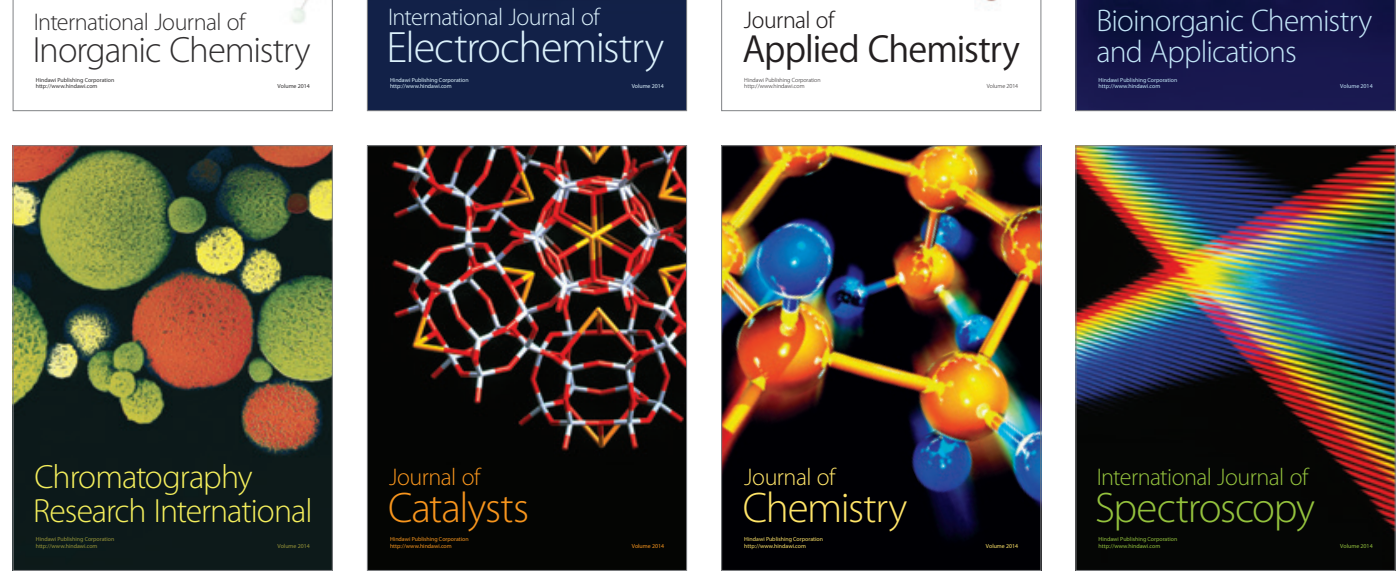